EMBRYARIDDLE
Aeronautical University

SCHOLARLY COMMONS
International Journal of Aviation, Aeronautics, and Aerospace

$11-7-2016$

\title{
A Validation of the Efficacy of Descriptive Instrumental Collective Case Study Research Methodology for Examining Pilot Cognitive Functioning
}

Clint R. Balog

Embry-Riddle Aeronautical University - Worldwide, balogc@erau.edu

Follow this and additional works at: https://commons.erau.edu/ijaaa

Part of the Cognition and Perception Commons, and the Cognitive Psychology Commons

\section{Scholarly Commons Citation}

Balog, C. R. (2016). A Validation of the Efficacy of Descriptive Instrumental Collective Case Study Research Methodology for Examining Pilot Cognitive Functioning. International Journal of Aviation, Aeronautics, and Aerospace, 3(4). https://doi.org/10.15394/ijaaa.2016.1094

This Article is brought to you for free and open access by the Journals at Scholarly Commons. It has been accepted for inclusion in International Journal of Aviation, Aeronautics, and Aerospace by an authorized administrator of Scholarly Commons. For more information, please contact commons@erau.edu. 
The aviation accident rate in the United States reached a plateau in the early 1970s and has remained relatively stable ever since (Hunter, 2002). During the subsequent time period, as aircraft and their components have become increasingly more reliable and less susceptible to failure, the National Transportation Safety Board (NTSB), the federal agency tasked with investigating aviation accidents, has implicated pilot error as the probable cause or the primary contributing factor in almost $80 \%$ of all such accidents (Balog, 2004; Hunter, 2002). Of all accidents in which pilot error is implicated, it is risk assessment and decision errors, or mistakes in the decision-making process, which the NTSB has determined are most often the root cause (Balog, 2004). Therefore it seems reasonable to conclude that to reduce this long-stable accident rate requires reducing the instances of pilot error, most directly and efficiently through an improvement in the risk assessment, problemsolving, and decision-making processes employed by pilots.

Fundamental to the accomplishment of this goal is the development of a clear understanding of how pilots employ the cognitive processes of risk assessment, problem-solving, and decision-making, particularly during in-flight emergencies. Of these, extended, extreme in-flight emergencies are the most challenging. They involve both considered and significant cognitive processing, rather than cognitive reaction, to resolve, and they produce the greatest magnitude of challenges to the employment of those processes (Balog, 2004; Hunter, 2002; O'Hare, 2006). Reducing the aviation accident rate, then, will necessitate an understanding of the interaction between the physiologic functioning of the brain and the psychological operation of the mind, as both are fundamental to these cognitive processes. From this understanding can then be developed the tools and methodologies necessary by which to begin to "build a better pilot": to train pilots to function more successfully during extended, extreme in-flight emergencies, thus leading to a reduction in the stubbornly steady aviation accident rate.

\section{Background of the Problem}

Extended, extreme in-flight emergencies present pilots with arguably the greatest cognitive challenges in flight operations. Each one is unique and likely never before experienced, certainly in their specific characteristics, resulting from a series of circumstances and events mostly unpredictable to the aircraft development teams. The flying public as a whole is often familiar with many of them, even those who are not associated with professional aviation because they often make the news. United Air Lines Flight No. 232 in Sioux City, Iowa, in 1989, which lost all three hydraulic systems (and thus normal operation of the flight controls) when the No. 2 engine suffered a catastrophic failure of a first stage fan disk in flight, and Aloha Air Lines Flight No. 243 in Maui, Hawaii in 1988, which 
had an eighteen-foot section of the upper fuselage just aft of the cockpit separated in flight, are just two examples. What makes these events so challenging for flight crews is that, for them, there are no manufacturers defined and certified emergency procedures and, to the researcher's knowledge, little or no previous operational experiences that directly relate to such events. Flight crews, and particularly the PICs, are left to resolve these challenging situations using only a database of technical and operational knowledge, and the higher level human cognitive skills of risk assessment, problem-solving, and decision making. What makes it challenging for researchers to examine them is that quantitative research methodologies are of little or no use in doing so and most qualitative methodologies are not applicable to the complexity and uniqueness of the circumstances. Therefore, what research to-date has not done well is develop a fundamental, descriptive understanding of the cognitive performance of pilots who successfully overcome these emergencies to use as a foundation for further research. This research effort was intended to accomplish that and at the same time validate the applicability and efficacy of Robert Stakes' 1995 descriptive, instrumental collective case study research methodology as a tool for investigating the human cognitive processes employed by PICs during such operational emergencies.

\section{Statement of the Problem}

While there has been much studied and written with regard to the cognitive processes of risk assessment, problem-solving, and decision-making, as well as the related concepts of judgment and reasoning, it has most often been within the confines of their fundamental and theoretical foundations of cognitive psychology. The predominance of this information is generalized in nature, not related to a specific environment, and is framed in routine (as compared to non-routine, or emergency) circumstances and static rather than dynamic environments (Glockner

$\&$ Betsch, 2008; O'Hare, 2006). Non-routine circumstances and vibrant environments tend to produce greater cognitive challenges for the operators, resulting from increased and continually changing stressors, than do routine circumstances and static environments (Sternberg \& Sternberg, 2017). What is largely missing from this wealth of information is the development of direct relationships between these cognitive processes and specific environments and circumstances, including dynamic environments and off-nominal and non-routine circumstances that explore specific practical applications of the cognitive processes (O'Hare, 2006; Sternberg, Kaufman, \& Grigorenko, 2008). This is, in part, due to the lack of methodologies fully applicable to the fundamental goal of the development of a detailed understanding of how the cognitive processes of risk assessment, problem-solving, and decision-making are successfully employed in such environments. Stakes' 1995 descriptive, instrumental collective case study 
research methodology was selected for this research as this is the essence of qualitative inquiry in general and case study inquiry specifically (Stake 1995; Yin, 2009). In this study, the environment of focus was cockpit flight operations.

\section{Purpose of the Study}

The goal of this research was intended to begin to fill in this information gap by developing an in-depth, descriptive understanding of how these cognitive processes are practically and employed. This, then, serves as a first step in the potentially lengthy process of improving the success rate in overcoming extended, extreme emergencies in such dynamic and complex environments.

As a result of accomplishing this purpose, this study will also validate the applicability and efficacy of Stakes' 1995 descriptive, instrumental collective case study research methodology as a tool for investigating the human cognitive processes employed by PICs during such operational emergencies. It will also expand that applicability to do so to other similarly dynamic environments engendering non-routine circumstances.

\section{Research Methodology}

Generally, qualitative analysis, and specifically case study research provides insight into the phenomenon being studied that is of greater depth, detail, and textural richness than provided by quantitative analysis (Miles \& Huberman, 1984; Stake, 1995; Yin, 2009). This general intent helps define this research project's specific intent to develop a holistic, thick, and detail-rich descriptions of the cases and their setting in their entirety to result in a vicarious understanding of the cognitive processes employed by the participants. This depth results from the nearly limitless categorical distinctions into which the participant's responses can be fit. The descriptive instrumental collective case study methodology, based upon Robert Stake's 1995 model, was selected for this research for a specific reason.

Fundamentally, the research purpose was to develop a holistic understanding of the phenomenon. That the research question asked for a description of an event occurring over a limited period was indicative both of case study methodology generally, and of a descriptive case study specifically (Stake, 1995; Tellis, 1997, Yin, 2009). The interest in the individual cases was not intrinsic to those cases themselves, but rather as the instruments to understanding the general problem. This, then, made this research an instrumental case study (Stake, 1995). Because the goal was to understand something other than the case itself and no two cases of extended, extreme, in-flight emergencies are the same (the specific 
circumstances of such events vary widely) it added value to the research to study more than one case. Studying more than a single case then made this a collective case study (Stake, 1995, 2006) also referred to as a multiple case study (Yin, 2003, 2009).

Stake's collective case study methodology requires that the size of the sample population is between eight and 14 and that it finally be determined by the number needed to reach data saturation. Saturation is that point at which additional instances of evidence (incidents, events, or activities) that represent a particular category of data no longer provide further insight into the understanding of that category (Hamel, Defour, \& Fortin, 1993; Stake, 2006). Saturation thus aids in ensuring a maximum of study credibility and dependability. Ultimately, data saturation was reached with eight research participants. The researcher stopped the data gathering process at this point.

\section{Participant Recruitment}

The researcher began building a pool of potential participants by employing the criterion sampling technique of specifically recruiting participants who had experienced the phenomenon of interest, an extended, extreme in-flight emergency, by requesting specific professional pilot organizations distribute to their membership a participant recruitment letter via a widely distributed email. This letter described the research being conducted and allowed for potential participants who are interested in participating to contact the researcher. This self-selection methodology ensured that any contact between a potential participant and the researcher was initiated by the potential participant. It also provided for initial recruitment to an extremely broad population. The researcher began this process with the three organizations that are the most widely accepted in the industry and which engender the largest professional pilot membership ranks, those being the Airline Pilots Association (ALPA), the National Business Aviation Association (NBAA), and the Aircraft Owners and Pilots Association (AOPA). In pursuing these three organizations the researcher covered all the key segments of professional pilots; commercial, corporate/business, private, civilian, and military.

The researcher simultaneously pursued two other recruitment paths. The first involved a former employer of the researcher in the field of corporate aviation training. This employer distributed a specific and limited number of these recruitment letters to its clients. The second was the repeated publication of the recruitment letter by an academic colleague's industry-distributed electronic safety newsletter. 
The researcher began narrowing the field of potential cases using an extreme case purposeful sampling technique (Stake, 2006; Yin, 2003, 2009). Having already met the fundamental criteria for the study and been recommended for their appropriate and strong relation to the study focus areas, this process selected those cases that best represent the criterion of "successfully overcoming" the extended, extreme in-flight emergency, as that criterion had been previously defined. The potential in this was that such flight operations successes might potentially have been revealed to have been derived from the strongest and most successful application of the cognitive processes that are of central interest in this study. This also helped to ensure the cases selected were among the most information rich and informative to the broader study purpose and thus were cases from which the most could learned in this study (Stake, 2006; Yin, 2003, 2009).

The final selection of cases resulted from an application of an intensity sampling of the already narrowed field (Stake, 2006; Yin, 2003, 2009). This process selected those cases that most intensely manifested the specific phenomenon of interest; that being the employment of the risk assessment, problem-solving, and cognitive decision-making processes by PICs during extended, extreme in-flight emergencies. This additional step in the selection process at first proved more parallel in nature to the extreme case sampling technique previously applied, helping confirm the cases selected during that process. They did, however, ultimately become more serial in nature, further eliminating potential cases to the final selection. The researcher accepted the first eight cases to meet the full criteria defined by this selection process.

To answer this collective case study research question the researcher needed to have participants who had shared the intense experience of the phenomenon (Stake, 2006). This and the very nature of qualitative inquiry (Stake, 1995, 2006; Yin, 2003, 2009) supported the application of a purposeful non-probability sampling procedure. The fundamental principle of the Belmont Report regarding the selection of participants for human research is that there must be fair procedures and outcomes in the selection of research participants (National Commission for the Protection of Human Subjects of Biomedical and Behavioral Research, 1979). With this sampling, procedure participants were purposefully identified and selected to participate based upon specific, predefined criteria specifically linked to the desired phenomenon of interest. Those same standards were applied to all potential participants and were blind to all criteria not specified in the development of the research methodology. 


\section{Summary of Participant Demographics}

The participant ages at the time of the interviews ranged from the early $50 \mathrm{~s}$ to the late 60s. Their ages on the date of the in-flight emergency experience ranged from the mid-20s to the mid-50s. All eight participants were Caucasian males and remained actively involved in aviation at the time of their respective research interviews. Five of the eight remained active pilots at the time of the interviews. At the time of the subject emergency one pilot was very low operational experience and flight time; one was of low operational experience and flight time; one was of moderate operational experience and flight time; two were of high operational experience and flight time; three were of very high operational experience and flight time (as these terms are generally accepted in the field). Six of the eight participants had past military flight experience. Six of the eight subject emergencies involved a civilian flight operation; two involved a military flight operation.

Of the six civilian flight operations involved two were private flight operations conducted under FAR Part 91 (or the non-U.S. equivalent); one was a corporate operation conducted under FAR Part 91; three were commercial operations conducted under FAR Part 121 (or the non-U.S. equivalent), and two were conducted under military flight operations regulations. One of the in-flight emergencies involved a single-engine, piston-powered aircraft; two involved twinengine, turboprop powered aircraft; one involved a twin-engine, turbojet-powered commercial aircraft; two involved four-engine, turbojet-powered commercial aircraft; one involved a twin-engine, subsonic turbojet powered military training aircraft; one involved a twin-engine, turbojet-powered supersonic military tactical training aircraft.

\section{Data Collection}

The primary source of data for this study was that gathered through informal, guided interviewing of the participants. This was logical given the stated purpose of the study, to develop a deep and rich understanding of participants' experience from his or her perspective. The interview process consisted of an initial interview with the potential for a follow-up interview based on any new circumstances of the study, though no such follow-up interviews were ultimately required. From these predefined guiding questions, the researcher remained open and adaptable during the interviews to adjusting the interview protocol and specific issues as needed to be based upon the emergent nature of the of the data provided by the participant (Hamel et al., 1993). Before commencing with the specific guiding questions, the researcher asked the participant to do the following: 
"Generally describe your experience of an extended extreme in-flight emergency." The recorded interviews lasted between 53 and 104 minutes, with a median time of 77 minutes and an average duration of 74 minutes.

The participants were also asked to keep notes or a journal of thoughts and ideas regarding the phenomenon of interest, or as prompted by consideration after the interview, and to pass those on to the researcher after the initial interview is conducted, either before or during the member checking process.

The researcher elected to withhold selecting a specific theoretical framework during the data collection process. In this way he best allowed the data to lead the path of the research, maintained the generic nature of the quintain, and developed an unbiased, detailed, and clear understanding of the cognitive processes under investigation by providing as much separation as possible between the data and his own axiological and worldview philosophic assumptions and any predispositions and biases such a preselected framework would engender. In this way, then, the purpose of the research was fulfilled with the least amount of distorting researcher influence, allowing the researcher to compensate better for those biases throughout the research process.

A secondary source of data collection, related to the interviews, was through the employment of member checking. The researcher is employed member checking by returning to the participants to discuss and obtain feedback regarding the written transcript of each case. This process resulted in the collection of additional or supplemental data as each of the eight pilots participated in member checking.

\section{Data Analysis}

The resultant data analysis strategy that emerged from the associated methodological constructs was a multi-phased and sequential thematic analysis, with each layer building upon the former. It fundamentally followed Creswell, Hansen, Clark Plano, Morales (2007) data analysis spiral while incorporating the specific methodologies within the case study approach, and specifically followed Stake's $(1995,2006)$ methodologies for multi-case analysis. Fundamentally it was a series of identical individual case analyses for each instance undergoing data immersion/description, direct interpretation, categorical aggregation, and withincase analysis, in that order. In general, this analysis identified and defined any and all themes relevant to the research question that were found running through the case (Stake, 1995, 2006). After this was done an embedded analysis was conducted to identify those patterns and themes specifically related to the participant's 
application of the cognitive processes of risk assessment, problem-solving, and decision-making, and those defined influences on those processes (Stake, 1995, 2006). After the individual within-case analyses had been completed, an acrosscase analysis (thematic synthesis) was conducted to identify themes and patterns common to all or most of the individual cases as well as an interpretation of the integrated meanings of all the cases (Stake, 1995, 2006). Finally, naturalistic generalizations were developed from the data as a whole (Stake, 1995, 2006).

\section{Results}

The data collection and analysis methodologies yielded a tremendous amount of data from the eight research interviews. This large volume of data became a strength of the study by more fully informing the study, by providing a more complete and holistic understanding of the answer to the research question through an exceedingly thick and rich description, and by easily ensuring data saturation with the eight cases.

Throughout the course of the analysis phase of this research, the data had gradually revealed what had been both a surprisingly large number of themes as well as through a strong thematic consistency among the eight cases of extended, extreme in-flight emergencies studied. Moreover, what differences did exist within these thematic consistencies could often be explained regarding the differences in operational characteristics between the cases.

The execution of the descriptive, instrumental, collective case study methodology led to numerous naturalistic generalizations regarding the cognitive processes employed by the participants of the eight cases in successfully overcoming the extended, extreme in-flight emergencies. First among these generalizations was that the cognitive processing used in these environments occurs in four definable stages and these stages are intermixed as needed based upon the immediate circumstances of the emergency. The four cognitive stages generally and typically characteristically are:

1. Highly excited state of arousal; explosively or very rapidly evolving emergency; immediate operational needs such as getting the aircraft safe or understanding the nature of the emergency and its operational impacts; rapid, shallow, narrowly focused, least analytical, predominantly serial cognitive processing; very short duration (seconds to one or two minutes).

2. Moderately excited state of arousal; slowed evolution of the emergency; less immediate operational needs such as 
troubleshooting the problems in an attempt to restore the aircraft; slowing, broadening, and deepening (more considered), more analytical, combination serial and parallel cognitive processing; short to moderate duration (a few minutes).

3. Relatively low level of arousal; still slower or stabilized evolution of the emergency; less immediate operational needs such as developing a plan of action for successfully resolving the emergency; still more slowed, broader, deeper (more considered) highly analytical, intense, more parallel cognitive processing; moderate or long duration of from minutes to hours, depending on the circumstances of the emergency.

4. Stabilized or slightly elevated, though still relatively low level of arousal; stabilized evolution of the emergency; stabilized operational needs such as executing the developed plan of action and remaining vigilant for any challenges to that scheme; continued slow, broad, deep, (considered), less intense and more vigilant, analytical (though more relaxed and open to less-analytic processes), serial and parallel processing; moderate duration of a few minutes to some fraction of an hour.

It also became evident that despite differing specific circumstances, all the pilots studied similarly employed these cognitive phases methodically, logically, and in a highly organized and disciplined manner. There was a very complex web of both straightforward and complex cognitive processes and concepts were required. Decision-making was the principle higher order cognitive process employed. All other simple cognitive processes were used in support of decisionmaking. Risk assessment and problem solving were the two primary complex cognitive processes used to support decision-making.

It was also revealed that the overall process of overcoming these emergencies was, to an extent, error-tolerant. Perfection in the application of these cognitive processes was not required to overcome the emergency successfully. There was a level of arousal that proved beneficial that appeared to have both upper and lower bounds, beyond which cognitive functioning became less efficient and effective. The ability to prioritize and compartmentalize actions proved beneficial, possibly critical. All forms of memory were involved. Both bottom-up and topdown processing were involved. Greater levels of experience and training proved very useful. The pilots' ability to supplement his knowledge with knowledge from outside the cockpit while the emergency was in progress proved highly beneficial. 


\section{Discussion}

This research had one fundamental goal; to develop a foundational descriptive understanding of both the cognitive processes employed by pilots who have successfully overcome the worst of in-flight emergencies (extended, extreme in-flight emergencies) and how they had employed them in doing so. This desired understanding was to encompass both cognitive functioning generally and holistically, as well as risk assessment, problem-solving, and decision-making specifically. The purpose of this goal was to begin filling in an existing void in this understanding so as to initially point the way to further research and to ultimately lead to the development of methodologies to improve the ability of the overall pilot population to successfully address such emergencies, thus eventually reducing both the overall aviation flight operations accident and mortality rates. It was also desired that this understanding could be translated to other similar dynamic operational environments. In meeting this one fundamental goal the validity and efficacy of the descriptive instrumental collective case study methodology, defined by Robert Stake in 1995, would also be confirmed.

A review of the results indicates just such a foundational understanding was successfully developed. The described hierarchy and interrelationship of the use of the cognitive processes, risk assessment and problem solving in support of decision-making and simple cognitive processes in support of complex, provides the field with insight as to where to focus attention for future research and these methodologies to most efficiently and effectively produce the desired results. The understanding of the complexity of these interrelationships and overall processes, including the recognition that all forms of memory are involved, helps to define the magnitude of the task at hand during extended, extreme in-flight emergencies. Conversely, the understanding that these processes are employed in just four discernible and definable stages provides insight into an organizational schema that will allow future researchers and educators to most efficiently and directly attack the problem. It provides a simplifying structure to counter the inherent complexity of the processes themselves. The understanding that all pilots who successfully overcome these in-flight emergencies do so in very similar ways, using the same cognitive processes and stages, and facing the same influencing challenges regardless of the overall specific circumstances of the emergencies, further organizes the task at hand.

The fact that the means of successfully overcoming these emergencies is, to an extent, error-tolerant provides optimism for researchers, educators, and pilots alike that the ultimate desired results are realistically achievable since it is not likely that human error can be entirely eliminated. Similarly, the understanding that some 
level of arousal is beneficial to overcoming these emergencies is a positive result, and a reason for optimism since, under the circumstances such as those that comprise an extended, extreme in-flight emergency, some elevated emotional and physiologic arousal is a human inevitability.

The results of this research also included understandings that provide insight into possible immediate actions to be taken to begin improving both pilot abilities in overcoming these emergencies specifically as well as aviation safety in general. For instance, the understanding that all three major decision-making strategies (analytical, associative, and codified) are employed as needed and appropriate in overcoming these emergencies, as well as are the three primary risk strategies (risk homeostasis, the zero risk theory, and the threat avoidance model) provides immediate opportunity as these are all teachable strategies. Also, the ability to prioritize and compartmentalize actions during these emergencies involves techniques that can be taught. In fact, such teaching techniques and strategies already exist. Similarly, both bottom-up and top-down processing can likewise be taught, at least in theory, and then practiced. These processes can be taught in the classroom and best practiced in an advanced flight simulator.

Indeed, the results of this research even illuminate opportunities for pilots themselves to take action toward immediately improving their abilities to successfully overcome these extended, extreme in-flight emergencies. The understanding that greater levels of experience and training positively impact these abilities provides the opportunity for pilots to focus additional priority in their careers on obtaining such experience and training. The understanding that a pilot is supplementing his knowledge during such an emergency with supplemental knowledge (information from others outside the cockpit while the emergency is in progress) provides a similar opportunity. In fact, this understanding provides further descriptive evidence of the fundamental concept of CRM, and directly relates it to successfully overcoming these emergencies by highlighting its beneficial application in doing so.

There were some limitations to the study that must be mentioned. The first limitation was that the study, as conducted, involved only male participants. This was not by design, but rather by chance as a result of the voluntary nature of participation and by the male-dominated nature of the cockpit flight environment. The second potential limitation, also arising from chance associated with voluntary participation as well as the probability of experiencing the prototypical in-flight emergency during a professional piloting career, was that the pilots included in this study were all relatively older at the time of the research interview. The third potential limitation associated with this study was that the researcher is also a long- 
standing member of the same professional culture of interest as are the participants, that of professional pilots.

\section{Conclusions}

The research has found that the results and findings of this study provides further supportive evidence of, and supplements, the existing and previously reviewed related knowledge in the field of cognitive psychology generally, and with regard to the processes of risk assessment, problem-solving, and decisionmaking specifically. Furthermore, none of the findings of this research directly contradicts any of the current and previously reviewed knowledge regarding the higher order cognitive processes risk assessment, perception, and tolerance strategies; problem-solving and the problem-solving cycle; decision-making strategies or aeronautical decision making.

The research successfully met its first purpose of developing an in-depth, descriptive understanding of how these cognitive processes are practically and employed. It is reasonable to conclude that it did so quite certainly by providing a tremendous amount of both raw and analyzed data, as well as defined conclusions, that more fully inform the study and by providing a more complete and holistic understanding of the answer to the research question. That data saturation was reached in the procedurally defined minimum of eight cases further, substantiates these conclusions. This, in turn, infused the study results with a significant level of credibility. As a result, it helps fill in a knowledge gap and serves as a first step in the potentially lengthy process of improving the success rate in overcoming extended, extreme emergencies in such dynamic and complex environments.

Because of its success in satisfying this first purpose, it is reasonable to conclude that the applicability and efficacy of the employment of Stake's 1995 descriptive, instrumental collective case study research methodology as a tool for investigating the human cognitive processes employed by PICs during such operational emergencies have been substantially confirmed. This, then, confirms that the research also satisfied its second purpose to do so. In turn, through synthesis, this subsequently confirms the efficacy of the use of Stake's 1995 descriptive instrumental collective case study methodology as a valid tool for examining cognitive functioning in not only the pilot community in flight operations but with those operators in a variety of similarly dynamic environments engendering non-routine circumstances. Such environments would include, but not be limited to, nuclear generating station operations, as evidenced by both the 1979 Three Mile Island and 1986 Chernobyl accidents, as well as the offshore oil 
production industry, as demonstrated by the 2010 Deepwater Horizon oil rig accident. 


\section{References}

Balog, C. (2004). Risk assessment and aeronautical decision-making: The factors behind fuel exhaustion. Unpublished master's thesis, Embry-Riddle Aeronautical University, Daytona Beach, FL.

Creswell, J., Hansen, W., Clark Plano, V., \& Morales, A. (2007). Qualitative research designs: Selection and implementation. The Counseling Psychologist, 35(2), 236-264. doi: 10.1177/0011000006287390

Glockner, A, \& Betsch, T. (2008). Multiple-reason decision-making based on automatic processing. Journal of Experimental Psychology: Learning, memory, and cognition, 34(5), 1055-1073.

doi: 10.1037/0278-7393.34.5.1055

Hamel, J., Dufour, S., \& Fortin, D. (1993). Case study methods. Newbury Park, CA: Sage Publications.

Hunter, D. (2002) Risk perception and risk tolerance in aircraft pilots (Report DOT/FAA/AM-02/17). Washington, DC: Department of Transportation, Federal Aviation Administration, Office of Aerospace Medicine.

Miles, M., \& Huberman, M. (1984). Qualitative data analysis: A source book for new methods. Thousand Oaks, CA: Sage Publications.

National Commission for the Protection of Human Subjects of Biomedical and Behavioral Research. (1979). Ethical Principles and Guidelines for the Protection of Human Subjects of Research. Washington, DC: U.S. Department of Health, Education, and Welfare.

O'Hare, D. (2006). Cognitive functions and performance shaping factors in aviation accidents and incidents. The International Journal of Aviation Psychology, 16(2), 145-156. doi: 10.1207/s15327108ijap1602_2

Stake, R. (1995). The art of case research. Newbury Park, CA: Sage.

Stake, R. (2006). Multiple case study analysis. New York: Guilford Press.

Sternberg, R., Kaufman, J., \& Grigorenko, E. (2008). Applied intelligence. New York: Cambridge University Press. 
Sternberg, R. \& Sternberg, K. (2017). Cognitive Psychology ( $7^{\text {th }}$ ed.). Boston: Cengage Learning.

Tellis, W. (1997). Introduction to case study. The Qualitative Report, 3(3), Retrieved from Nova Southeastern University Web site http://www.nova.edu/ssss/QR/QR3-2/tellis1.html.

Yin, R. (2003). Applications of case study research (2nd ed.). Thousand Oaks, CA: Sage.

Yin, R. (2009). Case study research: Design and methods (5th ed.). Thousand Oaks, CA: Sage. 
Appendix

Interview Instrument

https://commons.erau.edu/ijaaa/vol3/iss4/4 


\section{Guided Interview Questions}

1. Overall, how would you describe the experience of having an extended, extreme, in-flight emergency?

2. How would you describe your aviation background and experience prior to the emergency?

3. How would you describe the events directly preceding the emergency?

4. How would you describe the development of the emergency situation?

5. How would you describe your initial feelings and emotions once you realize the nature of the emergency?

6. How would you describe your feelings and emotions during the emergency?

7. How would you describe how you analyzed the risks you were facing?

8. How would you describe the options you determined were available to you for solving the problems?

9. How would you describe the experience and process of developing those options?

10. How would you describe the decisions you made during the emergency?

11. How would you describe the experience of making those decisions?

12. How would you describe your feelings after having made the decisions you made?

13. How would you describe your feelings once the emergency was over and you were back on the ground?

14. During your professional flying career have you had other emergency situations occur? 